in winter and summer search the mountain tops for their stock, are the men best fitted to tell us about the habits of the bird. On observations made during such experiences Mr. White bases his own account. In the district with which this writer was acquainted, the kea always lived high up on the mountains, among rocks and boulders, a long distance above the forest-line; in such a situation, of course, berries and fruits were out of the question, and the bird appeared to live on lichen and any insects it could find. Even when the ground was covered with several feet of snow, and when roots and other food were out of reach, lichen growing on steep rocks would still be obtainable by the bird. The view that the diet of the kea generally consists of fruit and berries would thus appear to be erroneous.

It will be remembered that Wallace and others state that the kea regards the kidneys of sheep as a "special delicacy," and that it attempts to brirrow into its victim in such a way as to reach this part. Mr. White, however, opposes this prevalent view, and regards it as probable that the bird desires to obtain the blood of the sheep rather than the kidneys; and in support of this view states that he has never seen a dead sheep attacked by keas. The fact that the kea so frequently pierces the body of a sheep in the region of the kidneys is due to the position it takes on the back of its victim to maintain a firm hold-a position from which it cannot be easily dislodged, as it could from the head or rump of the sheep. In corroboration of this Mr. White mentions that sheep with long wool are more frequently attacked than animals with short wool; as apparently the long wool gives the bird better facilities for holding on with his feet when drilling a hole into the back of the sheep. It is not very easy to conjecture how this habit of attacking sheep was first acquired by the kea. In winter time the sheep are covered with snow, and often have icicles hanging to their wool ; and it is suggested by Mr. White that keas may have mistaken sheep so disguised for snow-covered patches of rock. It may further have happened that when searching the supposed rocks for insects the birds in some cases would taste the blood of the sheep. "When some of the birds had once found out that the blood of the sheep was good for food, others were soon initiated into the performance." It" is possible that in some such manner the kea may have gradually acquired this curious and unattractive habit which renders the bird such a pest to the New Zealand farmer.

$$
\text { W. Garstang. }
$$

\section{THE PENETRATION OF ROOTS INTO LIVING TISSUES.}

THE capacity possessed by the roots of certain parasiles, such as Cuscuta, to penetrate into the tissues of their host, is apparently an unique, not to say a remarkable phenomenon. A little reflection, however, upon the powers of roots in general, leads us to doubt whether this property is really as restricter as the first glance would lead us to imagine; and when we pernse Prof. Pfeffer's work upon the pressure of the root, and find that, for instance, the root of the common bean exerts during its growth a pressure of some $400 \mathrm{gms}$., we realise that this mechanical action alone might suffice to drive the growing root of most plants into living tissue, if circumstances necessitated such an expediency. This is evidently an important point, and touches upon the evolution of the higher parasites; it is only remarkable that it has so long remained untouched. We must now thank George Peirce for taking up this neglected subject, and placing it upon a sure basis (see Bot. Zcit. September 1894). The question first to be decided was whether the pressure which Pfeffer had found in the growing roots was in itself sufficient to force the roots through living tissue. For the determination of this, iron models of roots weighted up to $270 \mathrm{gms}$. were employed. The apices of these were placed upon a cube cut from a potato, and the whole surrounded with damp sawdust to keep the living substance fresh. After an interval of twenty-three hours, it was found that the iron point had penetrated $1 \frac{1}{2} \mathrm{~m}$. m. into the potato. Again, a similar model weighted to $320 \mathrm{gmss}$. was driven in twenty-four hours through the cork layer and $2 \mathrm{~m}$. m. of parenchyma of an uncut potato. Also a root-model placed on the stem of Impatiens sultani, one and a half centimetres thick, pierced this in less than twenty hours when 300 gms. weight were employed.

Thus a pressure inferior to that found by Pfeffer in the root of Vicia faba was sufficient to drive an iron model an appreciable distance through the living tissues of the potato.
It was far from certain, however, whether a pressure which was ample to impel a rigid iron rodlet against a considerable resistance would have equal efficiency in the case of a root, the pressure in which arose from so uncertain and inextricable a source as its life.

There were many facts both pro and contra.

The acid substance or substances, which it would seem that most roots excrete during their growth, might possibly facilitate the root's power of penetration. Just as many fungi eat their way, as it were, into the solid wood of their host by means of ferment-like substances which they secrete and pour out upon their substratum, so might the roots perhaps be expected to soften and prepare their way by means of their acid excretions. Against the supposition could be raised the fact, already broached, that the forces, impelling the root-apex forward, are derived from the vital activities of that structure, and than these nothing can be more sensible to change of surroundings, or less to be reckoned upon by us, whose conceptions of anything dealing with life are yet shroucled over with the darkest obscurity.

But to pass from speculation to facts, we find that Peirce tested this point by experiments on the seedlings of Brassica napus and Sinapis alba. He took a potato, and split it in half on one of the halves he cut a number of small slits, into each of which he inserted a seed of the plant under observation. $\mathrm{He}$ then placed the potato-halves together, binding them tightly with string. The whole contrivance was placed in a vessel containing damp sawdust, care being taken that the cut surfaces of the tuber lay horizontally. After an interval of twelve days the specimens were examined, and although some were found to have grown between the cut surfaces (for nearly all had germinated), yet others had pushed their rootlets vertically downwards so as to penetrate the substance of the potato. In some instances so vigorous had been the growth that the rootlet had traversed the whole thickness of parenchyma, pierced the hard corky layer of the surface, and then reached the sawdust without.

Anatomical examination of the root and surrounding potato tissue showed several peculiarities. In the first place, the young root was almost devoid of the customary clothing of hairs; secondly, the cells of the potato had undergone alteration, inasmuch as those which were in immediate contact with the advancing root were much contorted and torn, whilst two or three layers neighbouring on the injured elements had undergone division by walls parallel to the long axis of the root, and had subsequently become corky in nature. By this means the intrusive rootlet was enclosed within a corky cylinder or sheath, cutting it off more or less perfectly from the living, unharmed tissue of the tuber. The starch grains were in every case unaltered, but Prunet, in his research on Cynodon, and Peirce, in his examination of one of his specimens of Pisum, noticed certain grains in the neighbourhood of the root apex which were partially disintegrated. This, however, is not a necessary consequence of ferment action ; indeed, a check experiment of Peirce's leaves little doubt that the disintegration results in these cases from the activities of bacteria which had gained an entrance with the root. Glass tubes closed and pointed at one end were sunk, like the iron models already mentioned, into potato tissue. In one instance the apex of the glass was surrounded by "corroded" starch-grains. Here there could be no question of ferment formation, and evidently bacteria were adherent to the apex.

"So far the experiments had proved that the thin, delicate, and pointed roots of rape and white mustard are able to penetrate living tissues. Peirce carried the matter further by testing the powers of the blunt rootlets of Pisum and Vicia faba to do likewise. The rootlets of germinating seeds of these were placed in glass tubes into which they accurately fitted, and their apices placed in contact with the surface of a cube of potato. The seed and glass tube were rigidly held by layers of gypsum, in which a gap was left for the extension of the plumule. The whole was kept moist by clamp sawdust. After three days the roots were found to have pierced the living tissue to the extent of $7.5 \mathrm{~m} . \mathrm{m}$.

Other experiments were made on the same plants in which other tissues, such as stem of Impatiens sultani, leaves of Echevaria and Aloe, petioles of Rheum, \&c., were substituted for the potato. These also were penetrated by the rootlets.

In some instances, however, such as leaves of Aloe and petioles of Rheum officinale, the pabulum was evidently un. suited to the healthy existence of the root, for after a short 
period of growth the apex of this organ became more or less spherical, and finally withered away.

Similar results had been obtained with the haustoria (modified roots) of Cuscuta, in a former research of George Peirce's.

Another interesting achievement of the same worker was to grow specimens of Pisum as parasites upon other plants, from the seedling stage until flowering. The host which gave the most favourable results appears to have been Impatiens sultani.

The young Pisum grown under these unwonted conditions produced an almost normal root system, with numerous side branches; but the stem was stunted in its growth, although it bore leaves and a few flowers. The roots, it may be mentioned, were here also devoid of hairs. This experiment is extremely interest. ing in a great many ways. It shows, in the first place, how fine is the line of demarcation between an ordinary earth-grown plant, such as Pisum, and a phanerogamous parasite, especially a partial parasite like mistletoe.

Again, it has a physiological interest ; it is suggestive of a new path of research. A strict and careful comparison of the details of outward form and internal anatomy in a normally grown Pisum, or other plant, with those found in one which is, so to speak, an induced parasite, must, beyond all doubt, shed much light upon the relationship between the shape and structure of an organism and its surroundings.

We know but too little of this branch of biology at present.

Why an organ should be shaped this way in one individua and that way in another, may indeed be partially answered in some cases ; but these instances are few, and the answers are in complete, to say the least of them.

RUDOIF BEFR.

\section{DR. A. SCHMIIIT'S THEORY OF,EARTH-} OUAKE-MOTION.

[NoTE.-The following pages contain a summary of an interesting but little known paper by Dr. August Schmidt, of Stuttgart. An English translation was prepared by the late Dr. E. von Rebeur-Paschwitz for the Seismological Journal of Japan, but arrived too late for publication in the concluding volume of the series. The original being too long for insertion in NaTURE, I have condensed it at the translator's request, at the same time adhering as closely as possible to the author's words. The title of the paper is "Wellenbewegung und Erdbeben ein Beitras zur Dynamik der Erdbeben " (Jahreshefte des Vereins fiur vaterl. Naturkunde in Wïrttemburg; I888, pp, 248-270). In a later paper (same journal, 1890, pp. 200-232), Dr. Schmidt applies his theory to the Swiss earthquake of January 7,1889 , and the Charleston earthquake of August 31, I886. - C. DAvison.]

SEISMOLOGISTS assume the propagation of earthquake waves to take place uniformly in all directions; they regard the coseismal or wave-surfaces as concentric spheres, the rays as straight lines normal to the spheres. This, however, is an entirely unjustified assumption, which certainly facilitates the calculations, but leads to very doubtful results in determinations of the velocity of propagation and of the depth of the earthquakecentre. It is impossible that seismic rays should be straight lines, because the conditions on which the velocity depends undergo change with increasing depth below the surface. Though experimental determinations of the velocity do not agree with the theoretical value $\sqrt{e / d}$, yet it is clear that the velocity must depend on the density and elasticity of the rocks through which the wave is propagated. Now, the modulus of elasticity, owing to increased pressure, must increase with the depth below the surface ; and therefore the velocity of the earthquake-wave must also increase with the depth.

As the velocity of propagation increases, the energy of a vibrating particle diminishes; and thus, as is well known to be the case, earthquakes should be less noticeable in mines than on the surface of the earth.

Amendment of Hopkins' Law.-Let us imagine a wave emanating from a deep centre and propagated in all directions. A vertical plane through the centre cuts all the successive coseismal surfaces, as well as the earth's surface. Let us suppose the section of the latter to be a horizontal straight line. The lower parts of Figs. I and 2 show the successive positions of the coseismal surfaces from minute to minute. Fig. I, with its equidistant concentric coseismals and its straight rays, corresponds to the ordinary earthquake theory. Fig. 2, with its excentric coseismals approaching each other as they rise and with its curved rays convex downwards, represents our new theory. The horizontal straight line, dividing the upper part of the figures from the lower, represents the surface of the earth. In both figures, the rays at first appear equally distributed in all directions from the centre; in Fig. I they remain so, but in Fig. 2 , in order to continue normal to the wave-surfaces, they must diverge at a much more rapid rate below than above, thus becoming convex downwards. Of course, Fig. 2 only represents a special law of increase of velocity with the depth-the velocity is supposed to vary as the depth-but the general character of the figure with its rays convex below remains the same if the law is a different one.

A comparison of the figures shows that in Fig. 2 there is a greater condensation of the seismic rays, and therefore a greater intensity of the shock, in the neighbourhood of the epicentre, and this corresponds better with the effects observed within the area of greatest disturbance.

But more important for our purpose are the sections of the earth's surface contained between two successive coseismals Each of these sections is a measure of the distance through which the wave appears to progress from minute to minute at the surface. In reality it progresses obliquely from below in the direction of the rays, and the real distance through which it moves is smaller than the apparent one. We can only observe the apparent velocity at the surface. If we have at our disposal a sufficient number of good time-observations, we can draw the horizontal coseismal lines on a map and determine the apparent velocity from their relative distances. In both figures, the apparent velocity has its greatest value at the epicentre and decreases outwards. In Fig. I, it gradually approaches asymptotically the true value in the direction of the rays. This is the law which Hopkins propounded in 1847 . In Fig. 2, the apparent velocity at first diminishes rather rapidly, until it reaches the value of the true velocity at the depth of the centre, but afterwards it again increases gradually with the distance. We thus arrive at the following amendment of Hopkins' law, which will be expanded afterwards : the apparent velocity at the surface is never less than the true velocity at the centre, and varies with it.

Differences in Earthquake Veloiities.-According to the old theory, every substance ought to possess its own velocity, dependent on its internal structure. The limit, which is defined by Hopkins' law as the lowest possible value of the apparent velocity, ought always to be the same in any given region. Experiments by Pfaff, Mallet, and Abbot lead to different values for different substances, as was to be expected. But they also show considerable variations in the same material, the velocity increasing with the strength of the initial impulse. Real earthquakes show even larger differences in velocity than artificial ones, and often carthquakes of less intensity are propagated with a greater velocity in the same region than very strong ones.

These differences are inconsistent with Hopkins' law. To be explained by the old theory, they require for the centres of earthquakes with great velocities an enormous depth below the surface, a near approach to the centre of the earth, for an earthquake emanating from the centre itself would arrive simultaneously at all points of the surface. With our new hypothesis, such differences are necessary, and even with the largest velocities the earthquake-centre may be at a considerable distance from the centre of the earth.

Proof of the Law. - The law that the velocity at the surface is never less than that at the earthquake-centre includes Hopkins' law. This indicates that the law is a general one. Its mathematical demonstration is contained in the law of refraction. We may distinguish the following three velocities: (I) the velocity at the centre, $u_{1} ;(2)$ the true velocity at the surface, i.e. that part of an earthquake-ray through which the wave progresses in one minute, $u ;(3)$ the apparent velocity at the surface, i.e. the horizontal distance between two successive coseismals corresponding to an interval of one minute, $v$. As an example, let us take in Fig. 2 the horizontal distance between the fourth and fifth coseismals from the epicentre as a representative of $v$, and let the section of the ray between the same coseismals near the surface represent $u$, and the distance between the centre and the first coseismal $u_{1}$. Then, if $\alpha$ be the angle between the ray and the vertical at the point where it meets the surface, we have $v=u / \sin \alpha$; and, if $\alpha_{1}$ be the angle which the same ray makes with the vertical through the earthquake-centre, we have by the law of refraction $v=\imath / \sin \alpha=u_{1} / \sin \alpha_{1}$.

Now, let us consider the different rays emanating from the

NO. 13.56 , VOL. 527 